\title{
The Relationship Between Interpersonal Cognitive Distortions and Attribution Styles Among Divorce Applicant Couples and its Impact on Sexual Satisfaction
}

\author{
Morteza Mahdoodizaman, ${ }^{1}$ Samira Razaghi, ${ }^{1}$ Lili Amirsardari, ${ }^{2,}$ Omran Hobbi, ${ }^{1}$ and Davod Ghaderi ${ }^{3}$ \\ ${ }^{1}$ Department of Psychology, Science and Research Branch, Islamic Azad University, West Azarbayjan, IR Iran \\ ${ }^{2}$ Young Researchers and Elite Club, Central Tehran Branch, Islamic Azad University, Tehran, IR Iran \\ ${ }^{3}$ Department of Psychology, Urmia Branch, Islamic Azad University, Urmia, IR Iran \\ "Corresponding author: Lili Amirsardari, Young Researchers and Elite Club, Central Tehran Branch, Islamic Azad University, Tehran, IR Iran. Tel: +98-9373242931, Fax: \\ +98-2833552093, E-mail: l.amirsardari@yahoo.com
}

Received 2016 February 20; Revised 2016 July 08; Accepted 2016 August 26.

\begin{abstract}
Background: The current study aimed to investigate the relationship between cognitive distortions and attribution styles among divorce applicant couples and its impact on sexual satisfaction.

Materials and Methods: It was a cross-sectional study and its statistical samples were 55 divorce applicant couples (110 individuals) referred to Urmia courts, Urmia, Iran, from 2012 to 2013. The required data were gathered by interpersonal cognitive distortions, Larson sexual satisfaction and attribution style questionnaire.

Results: The findings of the research indicated the existence of a significant relationship between attribution styles for pleasant events and cognitive distortions. The results showed that an increasing amount of pleasant events reduces cognitive distortions among the divorce applicant couples $(\mathrm{P}<0.05, \mathrm{r}=0.19)$. Attribution style has a significant relationship with sexual satisfaction among the divorced couples. As stable-unstable variables increase $(\mathrm{P}<0.05, \mathrm{r}=0.22)$, pleasant events, $(\mathrm{P}<0.05, \mathrm{r}=0.19)$, attribution styles (total) $(\mathrm{P}<0.05, \mathrm{r}=0.19)$ and sexual satisfaction increases and vice versa. Also, there was no significant relationship between sexual satisfaction and cognitive distortions $(\mathrm{P}<0.05, \mathrm{r}=0.04)$.

Conclusions: Normal and abnormal cognitive components are among the main factors affecting satisfaction or dissatisfaction in couples who are living together (sexual satisfaction is one of its main elements).
\end{abstract}

Keywords: Attribution Styles, Cognitive Distortions, Sexual Satisfaction

\section{Background}

Given Iran transition from a traditional society to a society of industry and modernism, family issues and communication problems are the most important problems of the families in the realm of mental health (1). Plenty of reference to family therapy centers and crisis intervention and increasing special help-seeking behavior show the existence of a serious problem in families' mental health (2). Divorce is the result of the most acute and serious communication problems of the family. Unfortunately, in terms of divorce and marriage ratio, Iran is among the first seven countries in the world (3). One of the causes of divorce is sexual dissatisfaction (4). Sexual desires and needs have an essential role in marital life. Sexual pleasure makes couples ignore many of daily life problems and marital disputes and increases emotional dependency between them (5). People who have a high level of satisfaction with their sex partner report a considerably better quality of life com- pared to those who are not satisfied (6). Ignoring the problem without solving it, endangers marital relationship and causes conflicts. Some of the destructive effects of marital conflicts can be named as physical consequences and increased risk of different types of mental disorders such as depression, drug addiction, sexual dysfunction and behavioral problems (7). Numerous studies show that the most common cause of marital conflict is the result of inappropriate sexual relationship; if for any reasons, there is no healthy sexual relationship between couple, one of the partners will be unhappy, disappointed and bored and it will cause conflicts and communication problems between them (8). Hulbert and Farley stated that dissatisfaction of sexual performance is closely related to divorce and social problems such as crimes, sexual assaults and mental illnesses. In this regard, Bentovim, in a quotation from Johnson and Masters, believed that the cause of $50 \%$ of marriage failures is sexual dissatisfaction (7). One of the 
cognitive models recently raised to explain family problems, which has gained a lot of attention due to its theoretical basis and strong experimental background, is cognitive model (9). According to this model, irrational beliefs and cognitive distortions are the important factors in creation and continuation of pathological behaviors (10). Recently, the research literature in this area is more specific and is focused on inefficient beliefs in relationships. An example for that are thoughts and beliefs about interpersonal relationships with spouse, relationships between parents and children's relationships (11). Firish, in a research program to explain a structural model of cognitive factors, sexual satisfaction and quality of life, showed that both for males and females, cognitive factors and attitudes, a causal relationship and subsequently sexual satisfaction, marital relationship quality and stability of marriage are involved (3). People's reaction to situations is influenced by their cognitive assessment and interpretation of situations; this is derived from a theory that gained attention in the last two decades and is based on individuals' explanation style for stress-inducing events that can have an important role in mental health and can be named as attribution theory (9). The purpose of attribution theory is to examine how people give causal explanations, how people respond to questions that begin with why, explaining the processes of events and emotional and behavioral consequences arising from these explanations (9). Individuals continuously choose specific causes for good and bad events that are sometimes incompatible attributions. In other words, attributing negative events to internal causes, and attributing general, stable and positive events to external causes without stability and specificity; these are called incompatible attribution styles and theses incompatible; in other words, pessimistic attributions are associated with psychological and physical problems (9).

\section{Objectives}

The current study aimed to determine the the relationship between cognitive distortions and attribution styles among divorce applicant couples and its impact on sexual satisfaction.

\section{Materials and Methods}

It was a cross sectional study. Statistical population of the study was divorce applicant couples (281 people referred to courts in the first four months of 2014) referred to family courts or divorce reduction centers (green opportunities) of Urmia welfare organization, Urmia, Iran. Accordingly, 55 couples were selected by convenience sampling method. The total sample involved 110 people, 55 females and 55 males. It should be mentioned that others who referred to divorce reduction centers individually (husband or wife) were excluded from the study and the statistical sample involved 55 couples referred to the same center. The questionnaires were filled by the couples who applied for divorce and then, they were collected by one of the authors in the court. Anonymous questionnaire was prepared to ensure that the results obtained by the participants in the study would not hurt anyone.

Measuring instruments were as follows:

1) Interpersonal cognitive distortions scale: the scale is designed by Hommamci (2004) to assess cognitive distortions in interpersonal relationships based on Aaron T. Beck's cognitive theory. This scale consists of 19 items (questions) in three subscales. The first subscale is called rejection in interpersonal relationships and includes eight items. The second subscale is unrealistic expectations in relationships and consists of eight items. The third subscale is misperception of interpersonal relationships and involves three subscales. Psychometric studies reported a high psychometric quality for this scale. Its reliability was checked through internal consistency by Cronbach's alpha and test-retest after two weeks. The results showed that the obtained Cronbach's alpha coefficient for the whole scale was 0.67 , in test-retest 0.74 and for its subscales 0.72 , 0.76 and 0.74 , respectively (3). Convergent validity was confirmed by correlation with other scales and factor analysis. The correlation of its scores with the scales of irrational beliefs, spontaneous thoughts and conflicts in interpersonal relationships were $0.45,0.53$ and 0.53 , respectively with a significance of 0.99 . The scale consists of 19 items that comprise three subscales. The first subscale is rejection in interpersonal relationships and includes eight items. The second subscale is unrealistic expectations in relationships and consists of eight items. The third subscale is misperception in interpersonal relationships and consists of three items.

- Questions of rejection in interpersonal relationships subscale: 1 - 3 - 10 - 12 - $13-14-15-19$

- Questions of unrealistic expectations in relationships subscale: 5 - 7 - 8 - 9 - 11-16-17-18

- Questions of interpersonal relationships misperception subscale: 2 - 4 - 6

According to this scale, respondents are placed in four groups based on the use of their cognitive distortions: no use, little use, relative use and full use. According to the selected choice, a score between one and five is given to each question and at the end, given the total obtained score (the sum of all scores) they are classified into four groups; therefore scores below 19 indicate no cognitive distortions use; from 19 to 38 low cognitive distortions use; from 38 to 57 relative cognitive distortions use and above 76 full cog- 
nitive distortions use (3).

2) Larson sexual satisfaction scale: Larson sexual satisfaction scale questionnaire has 25 questions with these choices: never, rarely, sometimes and always (7). According to this scale, respondents are divided into four groups of full satisfaction, relative satisfaction, low satisfaction and dissatisfaction. Given the selected choice in each question, each question is given a score from one to five, and at the end, based on their total score (the sum of all score) they are placed in four groups. Scores below 25 indicate no satisfaction; from 25 to 50 low satisfaction; from 50 to 100 relative satisfaction and above 100 full satisfaction. In Iran, this questionnaire was used by Shams and Mofarah in their study. Rahmani et al. used this questionnaire in their studies in 2010 and 2011 and to determine the reliability of the instruments test-retest method was used and the obtained results in 2010 and 2011 were 0.86 and 0.86 , respectively (7).

3) Attribution style questionnaire: this questionnaire is a self-report instrument and was first used to measure individuals' attributions for uncontrollable events. Attribution style questionnaire includes twelve hypothetical situations (six good events and six bad events). For each event, four questions are raised. The first question is about the most significant reason for the event, and although it is not used in scoring, the subject is required to respond to its following three questions. These questions include internal or external, stable or unstable and general or specific events. Scores can be given to each of the three mentioned aspects; for example, the internal-external aspect is obtained from the total score of the first question. If someone is in the position of total success and in the first question he checks items $6,4,2,3,5,4$, this person's internalexternal score will be the sum of these numbers divided by six. For attribution style questionnaire's reliability, Cronbach's alpha coefficient was 0.8 (12). Cronbach's alpha coefficients were $0.75,0.43,0.73,0.74,0.56$ and 0.76 for internal failure, stable failure, total failure, internal success, stable success and total success, respectively. Cronbach's alpha for the questionnaire was 0.74 . The range of 36 questions is from 36 to 144 . If the subjects' total score is below 144 , they are introvert and as their scores get closer to 36 , they are more introverted. If the score is above 144 , the subject is extrovert and if it is closer to 252 , he is more extroverted. The questionnaire of attribution style consists of twelve hypothetical situations with six good events and six bad events. Four questions are raised for each event. The first question is about the most important cause of the event, although it is not used in scoring, it is necessary for subjects to respond to the following three questions based on these aspects: internal or external, stable (steady) or unstable and general or specific events. Scores can be considered for each of these three dimensions, for example, internal-external di- mension is obtained from total score of the first question. If a person marks items 4 - 5 - 3 - 2 - 4 - 6 for success situation and the first question, the score of this person for the internal-external dimension is the sum of the numbers divided by six $24.6=4$; therefore, the score is calculated in the same way for other dimensions such as failure situation (13).

Pearson correlation coefficient and T-independent groups were provided, and SPSS version 20 (SPSS Inc., Chicago, IL, USA) was used to analyze the data.

\section{Results}

\subsection{Descriptive Findings}

The investigated samples of the study are presented separately in Table 1 based on gender and educational level.

Table 1. Separate Distribution of the Studied Samples Based on Gender and Educational Level ${ }^{\mathrm{a}}$

\begin{tabular}{lcc}
\hline Educational Level & Female & Male \\
\hline Master degree & $7(7.3)$ & $1(0.9)$ \\
Bachelor & $10(18.2)$ & $9(2.8)$ \\
\hline Associate degree & $2(3.6)$ & $2(1.8)$ \\
\hline High school diploma & $16(1.29)$ & $20(2.18)$ \\
\hline High school degree & $23(4.81)$ & $23(20.9)$ \\
\hline
\end{tabular}

${ }^{\mathrm{a}}$ Values are expressed as No. (\%).

In the study, the educational degree of $62.7 \%$ of the subjects (43 cases), males and females who were divorce applicants was below high school diploma and that of $47.3 \%$ (36 cases) had high school diploma. The investigated sample based on age at the time of divorce.

In the study $42.6 \%$ of divorce applicant couples (47 people), were in the age range of 26-35 (Table 2). The average age of the sample was 29.61 at divorce time.

Table 2. Frequency Distribution of the Sample Based on Age at the Time of Divorce ${ }^{\mathrm{a}}$

\begin{tabular}{lc}
\hline Age Range, $\mathbf{y}$ & Index \\
\hline $\mathbf{1 5}-\mathbf{2 5}$ & $37(33.5)$ \\
$\mathbf{2 6}-\mathbf{3 5}$ & $47(42.6)$ \\
$\mathbf{3 6}-\mathbf{4 5}$ & $20(18.5)$ \\
$\mathbf{4 6}-\mathbf{5 5}$ & $5(4.5)$ \\
\hline $\mathbf{5 6}-\mathbf{6 5}$ & $1(0.9)$ \\
\hline
\end{tabular}

${ }^{\mathrm{a}}$ Values are expressed as No. (\%). 


\subsection{Inferential Findings}

To determine the relationship between cognitive distortions and attribution style of the divorce applicant couples, Pearson correlation coefficient was used.

According to Table 3, the correlation coefficients between the internal-external pleasant variables with interpersonal rejection was -0.25 , and it was -0.19 between external-internal pleasant and interpersonal cognitive distortions (total), which was significant $(\mathrm{P}<0.05)$; it means that, with $95 \%$ confidence interval, there was a negative significant relationship between these variables. The results of Table 3 showed that, the correlation coefficients of all other variables were not significant, which means that there was no significant relationship between these variables $(\mathrm{P}>0.05)$.

To determine the relationship between cognitive distortions and sexual satisfaction in divorce applicant couples, Pearson correlation was used.

The results of Table 4 shows that the correlation coefficient between the variables of interpersonal relationships rejection was 0.004 , for unrealistic expectations was 0.07 , for interpersonal misperception was 0.005 and for interpersonal cognitive distortions (total) was 0.04 ; for sexual satisfaction it was insignificant $(\mathrm{P}>0.05)$.

Pearson correlation coefficient was used to determine the relationship between attribution styles and sexual satisfaction among divorce applicant couples.

The results of Table 5 showed that the correlation coefficients between pleasant unstable-stable variables (0.22), pleasant events (0.19) and attribution style (total) (0.19), and sexual satisfaction variable were significant, which means with $95 \%$ confidence interval, there was a significant relationship between these variables and sexual satisfaction $(\mathrm{P}<0.05)$. The results in Table 5 also showed that, the correlation coefficient between pleasant internalexternal variables (0.16), pleasant specific-general (0.13), unpleasant internal-external (0.13), unpleasant unstablestable (0.14), unpleasant specific-general (0.12), unpleasant events (0.14) and sexual satisfaction variable were not significant, which means that there is no significant relationship between these variables and sexual satisfaction $(\mathrm{P}>$ 0.05).

\section{Discussion}

The current study aimed to investigate the pathology of interpersonal conflicts among divorce applicant couples and its impact on sexual satisfaction. The results confirmed the presence of some pathological factors such as unpleasant attribution style and cognitive distortions among couples. The results of investigating the relationship between cognitive distortions and attribution style showed a negative significant relationship between pleasant internal-external variables and rejection in interpersonal relationships, and pleasant internal-external interpersonal relationships and interpersonal cognitive distortions. It means that as pleasant internal-external variables increased, the extent of rejection in interpersonal relationships and interpersonal cognitive distortions (general) decreased and vice-versa. But no significant correlations were found between other variables.

The findings of the study were compatible with those of the study on the relationship between mental pathology of family relationships and cognitive vulnerability (inefficient attitudes and interpersonal cognitive distortions) (14). This study concluded that there was a significant relationship between interpersonal cognitive distortions, irrational beliefs in marital relationship and inefficient attitudes and marital conflicts. Marital conflicts were predictable based on the scores of cognitive distortions, irrational beliefs and inefficient attitudes in marital relationships. Thelwell et al. showed that three positive characteristics (hope, self-perception and suitable attribution styles) can result in predicting emotional adaptation and better learning for a learner (15), which were compatible with the results of the current study; for example, if the applied attribution style among couples is pleasant internalexternal, the extent of rejection in interpersonal relationships and interpersonal cognitive distortions (total) is reduced and vice-versa.

The other finding of the current research revealed no significant relationship between interpersonal cognitive distortions and sexual satisfaction. The results of the study were not compatible with those of Abrahim, Zeinedini and Maracy (14). In a research conducted on 60 people, referred to family therapy centers in Isfahan, Iran, to find the relationship between mental pathology of family relationships and cognitive vulnerability (inefficient attitudes and interpersonal cognitive distortions), the conclusion was reached that there was a significant relationship between interpersonal cognitive distortions, irrational beliefs in marital relationships and inefficient attitudes and marital conflicts. Marital conflicts were predictable based on the scores of cognitive distortions, irrational beliefs in marital relationships and inefficient attitudes. No research on the relationship between cognitive distortions and its relationship with sexual satisfaction was found to be compared with the result of the hypothesis.

The other finding of the current research indicated a significant relationship between some attribution styles and sexual satisfaction. The results showed a significant relationship between pleasant unstable-stable variables, pleasant events and attribution styles (general) and sexual satisfaction. As the pleasant stable-unstable variables in- 
Table 3. Pearson Correlation Coefficients Between the Variables of Interpersonal Cognitive Distortions and Attribution Styles

\begin{tabular}{|c|c|c|c|c|}
\hline Variables & Interpersonal Rejection & Unrealistic Expectation & Interpersonal Misperception & $\begin{array}{l}\text { Interpersonal Cognitive } \\
\text { Distortions (Total) }\end{array}$ \\
\hline $\begin{array}{l}\text { External-internal pleasant } \\
\text { stable }\end{array}$ & -0.25 & 0.10 & -0.14 & -0.19 \\
\hline Stable-unstable pleasant & -0.18 & 0.11 & -0.02 & 0.0 \\
\hline Specific-general pleasant & -0.08 & 0.11 & -0.16 & -0.02 \\
\hline Pleasant events & $0-0.16$ & 0.12 & 0.12 & 0.05 \\
\hline Unpleasant external-internal & -0.18 & -0.08 & -0.14 & -0.08 \\
\hline Unstable-stable unpleasant & 0.01 & 0.06 & 0.03 & 0.03 \\
\hline Specific-general unpleasant & 0.04 & 0.13 & -0.08 & 0.06 \\
\hline Unpleasant events & -0.07 & 0.04 & -0.08 & -0.03 \\
\hline Attribution style (total) & -0.13 & 0.09 & 0.12 & -0.05 \\
\hline
\end{tabular}

Table 4. Pearson Correlation Coefficients Between the Variables and the Components of Interpersonal Cognitive Distortions of Sexual Satisfaction

\begin{tabular}{|c|c|c|}
\hline Variables & Correlation Coefficients & Significance \\
\hline $\begin{array}{l}\text { Interpersonal relationships } \\
\text { rejection }\end{array}$ & 0.004 & 0.97 \\
\hline Unrealistic expectations & 0.07 & 0.44 \\
\hline \multicolumn{3}{|l|}{$\begin{array}{l}\text { Interpersonal } \\
\text { misperceptions }\end{array}$} \\
\hline $\begin{array}{l}\text { Interpersonal } \\
\text { relationships }\end{array}$ & 0.005 & 0.96 \\
\hline $\begin{array}{l}\text { Interpersonal } \\
\text { cognitive distortions } \\
\text { (total) }\end{array}$ & 0.04 & 0.66 \\
\hline
\end{tabular}

Table 5. Pearson Correlation Coefficients Between Attribution Style With its Components and Sexual Satisfaction $(\mathrm{N}=107)$

\begin{tabular}{|lcc|}
\hline Variables & Correlation Coefficients & Significance \\
\hline Pleasant external-internal & 0.16 & 0.08 \\
\hline Pleasant stable-unstable & $0.22^{\mathrm{a}}$ & 0.02 \\
\hline Pleasant specific-general & 0.13 & 0.16 \\
\hline Pleasant events & $0.19^{\mathrm{a}}$ & 0.04 \\
\hline $\begin{array}{l}\text { Unpleasant } \\
\text { external-internal }\end{array}$ & 0.13 & 0.17 \\
\hline Unpleasant unstable-stable & 0.14 & 0.15 \\
\hline Unpleasant specific-general & 0.12 & 0.19 \\
\hline Unpleasant events & 0.14 & 0.14 \\
\hline Attribution style (total) & $0.19^{\mathrm{a}}$ & 0.04 \\
\hline
\end{tabular}

${ }^{\text {a }}$ Correlation is significant at the level of 0.05 (2-tailed)

creased, pleasant events, attribution styles, and sexual satisfaction increased and vice versa. But there was no signif- icant relationship between attribution style variables and those of sexual satisfaction.

The results of a study on 20 Iranian couples, who referred to counseling centers in Isfahan, Iran, to find out the relationship between retraining attribution style and marital satisfaction showed that retraining attribution styles significantly increased sexual satisfaction (5). Another study showed a bilateral interaction between using attribution styles, a habitual approach in evaluation and processing of life events as well as explanatory flexibility to find the cause of the events (16). A study on attributions, cognitions and coping styles indicated that internal attributions were more associated with problematic coping styles; negative attributions (pessimistic) were associated with emotion-centered coping styles and negative psychological results, which were compatible with the results of the current research; in other words, if couples had optimistic explanatory style, their sexual satisfaction increased (16).

As a conclusion, it is advised to follow the same procedure on people in different cities, age groups, educational backgrounds and different cultures. Limitations of this research can be regarded as the use of self-reporting questionnaires that make it almost impossible to overgeneralize the results to other communities. It is advised that further studies investigate the relationship between interpersonal cognitive distortions, attribution styles and tendency to the divorce among couples.

\section{Acknowledgments}

Authors would like to thank all of the students who participated in the study. 


\section{Footnotes}

Author's Contribution: Morteza Mahdoodizaman: conceiving and designing the evaluation tool, collecting and interpreting the clinical data, performing the statistical analysis, and preparing manuscript draft; Lili Amirsardari, Samira Razaghi, Omran Hobbi and Davod Ghaderi: revising the manuscript for important intellectual content. All authors read and approve the final manuscript.

Declaration of Interest: There was no conflict of interests regarding the materials of the current study.

Funding/Support: There was no financial support for the current study.

\section{References}

1. Movahed M, Azizi T. Study of women's sexual satisfaction and conflicts between spouses, Women in Development \& Politics. Res Women. 2011;9(2):181-206.

2. Foroutan K, Milani A. Prevalence of sexual dysfunction in divorce referred to family court. Stud Edu. 2008;16(87):35-9.

3. Ebrahimi E, Zeynoldini S, Merasi MR. Inefficient attitudes and interpersonal Conatives. Esfahan Med UJ. 2011;29(167):36-48.

4. Rajabi G, Sotoudeh O, KhojastehMehr R. Effects of cognitivebehavioral group therapy in reducing depression and increasing satisfaction in women. Social Stud - Psychol Women. 2010;8(2):25-42.
5. Qurayshyan M, NeshatDoost H, Maulvi H. Iranian Attribution style re-education and marital satisfaction in couples, Developmental Psychology. Iran psychologist J. 2010;5(24):21-9.

6. Asgari $\mathrm{H}$. The role of mental health, marriage and divorce, printing, Tehran conversation. J Behav Sci. 2001;8(20):10-30.

7. Rahmani A, Sadeghi N, Ali Quli L, MerghatiKhoei E. Individual factors Relationship with sexual satisfaction in couples. Iran Un Med Sci (Nurs J). 2010;23(66):54-60.

8. NiaKayhan A. Youth and marriage.J Psychol Edu Sci. 2008;12(8):42-50.

9. Motamedi Sharek F, Afrooz G. Attributional Styles and Mental Health in Gifted Vs. Normal Students. [in Persian]. IJPCP. 2007;13(2):173-81.

10. Mousavi A. The relationship between attribution style and self-esteem of students. J Psychol. 2004;2(9):125-51.

11. KoohsarAhadi A, Moalem A. Coping with depression and attribution style bosses: the moderating effect of gender. New J Industrial Organ Psychol. 2011;2(6):97-105.

12. Hugelshofer DS, Kwon P, Reff RC, Olson ML. Humour's role in the relation between attributional style and dysphoria. Europ J Pers. 2006;20(4):325-36. doi: 10.1002/per.586.

13. Mahboudi M. Comparison of causal attribution styles for women (prostitutes) with normal women arrested. M.Sc. Tehran: AllamehTabatabai University in Tehran; 2008.

14. Abraham S, Zinedine J, Maracy L. The relationship between sexual issues \& marriage satisfaction. J Psychosom Res. 2011;108(1):50-76.

15. Thelwell RC, Lane AM, Weston NJV. Mood states, self-set goals, selfefficacy and performance in academic examinations. Pers Indiv Differ 2007;42(3):573-83.

16. Moore MT, Fresco DM. The relationship of explanatory flexibility to explanatory style. Behav Ther. 2007;38(4):325-32. doi: 10.1016/j.beth.2006.06.007. [PubMed:18021947]. 